\title{
Domiciliary continuous positive airway pressure therapy in an underserved population: compliance and influential factors
}

Tanisha S. Burke ${ }^{1 *}$, Mary Ellen Wells ${ }^{2}$ and Jaspal Singh ${ }^{3}$

*Correspondence:Tanisha.S.Burke@gmail.com

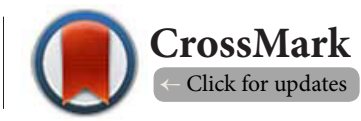

${ }^{1}$ Carolinas Sleep Services, University of North Carolina at Charlotte, Charlotte, North Carolina, USA.

2Department of Allied Health Sciences, University of North Carolina at Chapel Hill, Chapel Hill, North Carolina, USA.

${ }^{3}$ Carolinas sleep services, University of North Carolina at Chapel Hill, Chapel Hill, North Carolina, USA.

\begin{abstract}
Obstructive sleep apnea syndrome is an increasingly recognized global epidemic [1]. Uninsured patients frequently lack access to specialized testing, treatment and specialists access. Such patients may have conflicting priorities that affect their ability to comply with sleep apnea therapy. Carolinas Sleep Services has an Ambulatory Sleep program in which uninsured patients in Mecklenberg County, NC are provided both diagnostic and treatment options at either no or minimal charge. We retrospectively reviewed the chart data for 236 patients at the Carolina Sleep Services Ambulatory Clinic to assess patient adherence to PAP therapy in this low-income population. 149 (63\%) of the 236 patients were recommended to have positive airway pressure therapy; the remaining 87 patients were not recommended PAP therapies. Compliance reports were obtained for only 30 of the 149 patients; patients were not given CPAP devices with modems and the return of card data was a challenge. Of those with compliance reports, 14 (47\%) were compliant with their therapy. However, since this study had severe limitations, further research into methods for improving therapeutic compliance in uninsured or low-income populations is suggested. Approaches for addressing PAP compliance in underserved populations may also be linked to broader issues of access to healthcare in this population.
\end{abstract}

Keywords: Compliance, positive airway pressure therapy, underserved population, obstructive sleep apnea syndrome, sleep disorder

\section{Introduction}

Obstructive sleep apnea syndrome (OSAS) is an increasingly recognized global epidemic [1]. The current standard of treatment for moderate to severe OSAS is positive airway pressure (PAP) therapy [2]. However, diagnosis and treatment methods are expensive, and often unaffordable to those that are economically challenged and/or uninsured $[3,4,9]$. Reports in the literature suggest that patients from lower SES backgrounds encounter barriers to diagnosis of OSAS and have lower therapy adherence rates $[3,4,7,9]$.

Carolinas HealthCare System offers a sliding scale payment program for uninsured patients that live in Mecklenburg County. Carolina Sleep Services (CSS), in partnership with its sleep physicians and associated clinics in Mecklenburg County, attempts to serve those uninsured or low-income patients who are diagnosed with OSAS in a manner that improves access to care and reduces patient cost without sacrificing quality. As part of this, CSS instituted a telemedicine-based ambulatory clinic; eligible patients are Mecklenberg County residents who have established a primary care provider through the sliding-scale primary care clinic. Similarly, together with Carolinas Healthy at Home, CSS provides PAP treatment options to sleep apnea patients who are on a sliding scale and are uninsured.

Previous research has documented many reasons for nonadherence ranging from: affordability, the need for more OSAS pathophysiology and PAP therapy education, support from family/friends and medical providers, personal beliefs, disease perception, along with other factors. The inter-relationships of these factors pose a significant research challenge in OSA as well as other chronic disorders [3-7,9].

Untreated or undertreated OSAS can exacerbate comorbidities such as diabetes, atrial fibrillation, congestive heart failure, myocardial infractions, stroke, and therefore the effects of proper treatment and adherence may have broader impli- 
Burke et al. Pulmonology \& Respiratory Research 2014,

http://www.hoajonline.com/journals/pdf/2053-6739-2-1.pdf

doi: $10.7243 / 2053-6739-2-1$

cations $[3,8]$. The goal for this study was to assess compliance with PAP therapy and any associated factors that affected compliance in a low-income/uninsured population at home.

\section{Methods}

The ongoing CSS program followed the following protocol: Patients with a prior diagnosis of sleep apnea were sent directly to Healthy at Home for initiation of PAP therapy. Board-certified sleep physicians for further review and determination of appropriate testing screened patients without a prior diagnosis through the electronic health record. Patients with suspected sleep apnea were then referred to CSS-Mercy for a daytime sleep study with a limited channel hook up. Patients diagnosed with significant obstructive sleep apnea were then placed on an auto-titration PAP device to determine proper home settings. A refurbished or low cost PAP machine was then provided to the patients.

Selection criteria for the intended population included if the patient was underinsured or uninsured and had already met the qualifications to be on the sliding scale, based off of low household income, through Carolinas Healthcare System. The time frame used for the retrospective chart review was from January 1, 2011 to January 1, 2013. Demographic information used from the databases included age, gender, race, BMI. The diagnostic data from the daytime sleep study included the apnea hypopnea index and oxygen desaturation levels were also analyzed statically. Other variables in this population included diabetes, strokes, Atrial Fibrillation, Congestive Heart Failure and Myocardial Infraction.

We conducted a retrospective review of 236 patients seen in the Ambulatory Clinic between January 2011 and January 2013. Data was collected from Carolinas Healthcare System Electronic Health Record and from the Carolinas Sleep Services database. Information obtained from the databases included age, gender, race, BMI, diagnosis of diabetes and associated $\mathrm{HgbA1c}$ values, prior stroke occurrence, and diagnosis of atrial fibrillation, congestive heart failure and myocardial infraction. Diagnostic data analyzed from the daytime sleep study included the apnea hypopnea index and oxygen desaturation levels. The apnea hypopnea index was categorized using the American Academy of Sleep Medicine groups of mild (5-15 events/hour), moderate (15-30 events/hour), and severe ( $>30$ events/hour) [9]. We defined compliance as the use of the PAP machine by the patient for at least 4 hours per night. Data collation and analysis were performed using Microsoft Excel 2011. The statistical tests used to determine significance were Chi-square and t-tests. The study was approved by the Institutional Review Board (IRB \# 02-13-29E).

\section{Results}

Table 1 shows the demographic and clinical characteristics of patients referred for PAP therapy and those either not referred for therapy or who refused therapy and returned their machine. Patients who were not referred or who refused PAP tended
Table 1. Participant demographic and medical characteristics, by PAP therapy referral status (total $\mathrm{N}=236$ ).

\begin{tabular}{lll}
\hline Characteristic & $\begin{array}{l}\text { Patients referred } \\
\text { for PAP therapy } \\
(\mathbf{N}=\mathbf{1 4 9})\end{array}$ & $\begin{array}{l}\text { Patients not referred for } \\
\text { PAP therapy (or refused } \\
\text { therapy) (N=87) }\end{array}$ \\
\hline Race (n (\%)) & $114(77 \%)$ & $67(77 \%)$ \\
\hline Black & $26(17 \%)$ & $10(11.5 \%)$ \\
White & $9(6 \%)$ & $10(11.5 \%)$ \\
Other of unknown & $84(97 \%)$ \\
Female (n (\%)) & $49(33 \%)$ & 46.9 \\
Age (mean) & 48.2 & 35.4 \\
BMI (mean) & 40.1 & 2.5 \\
AHI (mean) & 29.7 & $89 \%$ \\
PSG oxygen & $83 \%$ & \\
saturation (mean) & & $12(14 \%)$ \\
\hline Diabetic (n (\%)) & & 0 \\
\hline $\begin{array}{ll}\text { Prior stroke (n) } \\
\text { Prior MI (n) }\end{array}$ & $63(42 \%)$ & 0 \\
Prior atrial & 1 & 0 \\
fibrillation (n) & & 0 \\
Congestive heart & 7 & 0 \\
failure (n) & & \\
\hline Sleep apnea level & & 0 \\
\hline $\begin{array}{l}\text { Mild } \\
\text { Moderate }\end{array}$ & $68(46 \%)$ & \\
Severe & $42(26 \%)$ & 0 \\
\hline Type of PAP therapy (n (\%)) & \\
\hline $\begin{array}{l}\text { Bi-level (n) } \\
\text { Continuous (n) }\end{array}$ & 147 & \\
\hline & & \\
\hline
\end{tabular}

to have lower $\mathrm{AHI}$ (mean $\mathrm{AHI}=2.5$ ) than those who were referred for PAP therapy (mean $\mathrm{AHI}=29.7$ ), had higher PSG oxygen saturations ( mean $=89 \%$ vs. mean $=83 \%$ for patients referred for therapy), younger in age (mean $=46.9$ years vs. 48.2 years for patients referred for PAP therapy) and lower BMI (mean=35.4 vs. 40.1 for patients referred for PAP therapy). With respect to existing medical conditions, significantly more people with diabetes were referred for PAP therapy, than those who were not referred or who refused therapy $\left(x^{2}(1)=34.68 ; p<0.0001\right)$. Of those participants referred for PAP therapy, none had a prior stroke, one had a prior $\mathrm{Ml}$, one had prior atrial fibrillation, and 7 had congestive heart failure. Of those participants who were not referred or who refused PAP therapy, none had prior stroke, $\mathrm{Ml}$, atrial fibrillation, or congestive heart failure.

Relatively few compliance reports were found for the patients who were referred to PAP therapy (and who did not refuse therapy-see Table 2). Although the presence or absence of compliance reports was not entirely due to patient characteristics, those without reports tended to have slightly higher $\mathrm{AHI}$ (30.1 mean $\mathrm{AHI}$ compared to $27.9 \mathrm{AHI}$ in patients with compliance reports), younger in age (40.4 mean age compared to 49 mean age of those with compliance reports), and slightly higher PSG oxygen saturation. Also, significantly 
Burke et al. Pulmonology \& Respiratory Research 2014,

Table 2. Participant demographic and medical characteristics, by presence of compliance report (for those on PAP therapy; $\mathrm{N}=149$ ).

\begin{tabular}{lll}
\hline Characteristic & $\begin{array}{l}\text { Patients with } \\
\text { compliance } \\
\text { reports (N=30) }\end{array}$ & $\begin{array}{l}\text { Patients without } \\
\text { compliance } \\
\text { reports (N=119) }\end{array}$ \\
\hline Race (n (\%)) & $25(83 \%)$ & $89(75 \%)$ \\
\hline Black & $4(13 \%)$ & $19(16 \%)$ \\
White & $1(3 \%)$ & $11(9 \%)$ \\
Other or unknown & $13(43 \%)$ & $58(49 \%)$ \\
Female (n (\%)) & 49 & 40.4 \\
Age (mean) & 39.2 & 40.4 \\
BMI (mean) & 27.9 & 30.1 \\
AHI (mean) & $82 \%$ & $83 \%$ \\
PSG oxygen saturation (\%) & $53(45 \%)$ \\
$\begin{array}{l}\text { Diabetic (n (\%)) } \\
\text { Prior stroke (n (\%)) }\end{array}$ & $10(33 \%)$ & $0(0 \%)$ \\
Prior MI (n (\%)) & $1(3 \%)$ & $0(0 \%)$ \\
Prior atrial fibrillation & $0(0 \%)$ & $1(0.8 \%)$ \\
(n (\%)) & & $4(3 \%)$ \\
Congestive heart failure & $3(0.1 \%)$ & \\
\hline Type of PAP therapy (n) & & -- \\
\hline $\begin{array}{l}\text { Bi-level } \\
\text { Continuous }\end{array}$ & 1 & 0 \\
Showed at follow-up & 29 & \\
appointments & 30 & \\
$\begin{array}{l}\text { Doctors' notes in charts } \\
\text { recorded that compliance } \\
\text { information was obtained }\end{array}$ & 30 & \\
\hline
\end{tabular}

more of the patients without compliance reports had a prior diagnosis of type two diabetes $\left(X^{2}(1)=29.349 ; p<0.0001\right)$.

Table 3 shows that only 14 patients (47\%) of the 30 with compliance reports complied with their PAP therapy. The range of hours of use was 4.35 hours to 9.54 hours, compared with the range of 0.51 hours to 3.5 hours for patients who were noncompliant.

Patients who were non-compliant tended to have higher AHI (29.7), higher BMI (40.3), younger (48) and have a prior diagnosis of type two diabetes; although the differences in $\mathrm{AHI}, \mathrm{BMI}$, and age were not statistically different. There was no significant difference in compliance with regard to sex $\left(x^{2}(1)=\right.$ $0.077 ; p=0.7815)$ or race $\left(\right.$ black, $\left.x^{2}(1)=0.040 ; p=0.8415\right)$ (white, $x^{2}(1)=1.000 ; p=0.3173$ ) (other, $x^{2}(1)=1.000 ; 0=0.3173$ ), when comparing compliant vs. non-compliant patients, both who had compliance reports $(\mathrm{N}=30)$. There was a high statistically significant difference in the hours per night patients who were compliant (with compliance reports) used PAP (mean=5.94 hours) compared to non-compliant patients, with compliance reports (mean $=1.97$ hours) $(p<0.0001)$.

\section{Discussion and Conclusion}

This study is consistent with previous research in that less than half (47\%) of participants with compliance reports are
Table 3. Participant demographic and medical characteristics, by adherence status, for those PAP therapy patients with a compliance report ${ }^{*}$.

\begin{tabular}{|c|c|c|c|}
\hline Characteristic & $\begin{array}{l}\text { Compliant } \\
\text { patients } \\
(\mathrm{N}=14)\end{array}$ & $\begin{array}{l}\text { Noncompliant } \\
\text { patients } \\
(\mathrm{N}=16)\end{array}$ & $\begin{array}{l}\text { p-value for } \\
\text { comparison } \\
\left({ }^{*}\right)\end{array}$ \\
\hline \multicolumn{4}{|l|}{ Race (n (\%)) } \\
\hline Black & $13(93 \%)$ & $12(75 \%)$ & 0.8415 \\
\hline White & $1(7 \%)$ & $3(19 \%)$ & 0.3173 \\
\hline Other or unknown & $0(0 \%)$ & $1(6 \%)$ & 0.3173 \\
\hline total & 14 & 16 & 0.7150 \\
\hline Female (n (\%)) & $6(43 \%)$ & $7(44 \%)$ & 0.7815 \\
\hline Age (mean (SD)) & $50(6.79)$ & $48(7.75)$ & 0.4957 \\
\hline BMI (mean (SD)) & $37.9(8.57)$ & 40.3 & $0.5492(12.07)$ \\
\hline AHI (mean (SD)) & $25.9(30.21)$ & $29.7(25.29)$ & 0.7079 \\
\hline $\begin{array}{l}\text { PSG oxygen } \\
\text { saturation (mean) }\end{array}$ & $82 \%$ & $82 \%$ & -- \\
\hline Diabetic (n (\%)) & $2(14 \%)$ & $8(50 \%)$ & 0.0578 \\
\hline Prior stroke (n (\%)) & $0(0 \%)$ & $0(0 \%)$ & -- \\
\hline Prior MI (n (\%)) & $1(0 \%)$ & $0(0 \%)$ & -- \\
\hline $\begin{array}{l}\text { Prior atrial } \\
\text { fibrillation (n (\%)) }\end{array}$ & $0(0 \%)$ & $0(0 \%)$ & -- \\
\hline $\begin{array}{l}\text { Congestive heart } \\
\text { failure }(\mathrm{n}(\%))\end{array}$ & $1(7 \%)$ & $2(12 \%)$ & -- \\
\hline \multicolumn{4}{|c|}{ Type of PAP therapy (n) } \\
\hline Bi-level & 0 & 1 & -- \\
\hline Continuous & 14 & 15 & -- \\
\hline $\begin{array}{l}\text { Hours per night used } \\
\text { PAP machine } \\
(\text { mean }(\mathrm{SD}))\end{array}$ & $5.94(1.75)$ & $1.97(1.75)$ & $<0.0001$ \\
\hline
\end{tabular}

${ }^{*}$ p-values for Age, BMI, AHI, PSG Oxygen saturation, and Hours per night used PAP machine are t-tests $(95 \% \mathrm{CI})$; all others are Chi-square tests.

compliant with PAP therapy.

One of the major limitations of the study was the number of compliance reports available from the electronic databases. Although there were some problems that were due to patient lack of adherence -e.g., 55\% of patients failed to show for follow up appointments -Table 2 shows that there were also providerrelated issues, including delays in setting up the PAP machines, provision of PAP machines without modem capacity, and improper use of the PAP machines with modem capacity. (With respect to the latter case, some providers did not use the recordings of nightly usage provided by the PAP machines but instead during follow-up visits but instead used a manometer to measure the machine's pressure level and asked patients for a verbal report of whether the machine was used on a nightly basis). Some of these are likely costrelated in source, but others are either ambiguous or suggest a practice-related concern. This suggests either that more PAP devices were being used with the capability to transmit nightly usage data or providers were becoming more aware of the need to track compliance.

Other operational or logistical issues that hindered the 
Burke et al. Pulmonology \& Respiratory Research 2014,

collection of compliance data included the following: no consistent notations of the actual type (brand of machine) of PAP device being issued, no tracking of the type of mask being issued, and no mention of whether humidifiers were being used with the PAP device.

Some of the problems and barriers reported by patients (Table 3) should be addressed on a population level. While issues such as how well the mask fits cannot be addressed globally, others, such as the affordability of the PAP machine, may be amenable to programmatic solution. Low-income or uninsured individuals often must prioritize their spending in favor of housing or food over medical expenses. The future potential costs due to OSAS-associated comorbidities may be preventable in this population if PAP therapy is made more affordable in terms of savings in time, effort, and monetary cost.

Enhancing compliance with PAP therapy will increase the treatment rate of OSAS, in turn improving an underserved community's health. In the future, programs addressing issues of affordability, tracking compliance, providing education on the hazards of sleep apnea, and training patients to use PAP devices and masks in this population will be key in cultivating PAP adherence. Moving forward, future research will face multifaceted obstacles in the pursuit to improve compliance to PAP therapy for OSAS for underserved communities. Uncovering commonalities in other diseases and the unique challenges within this population with accessing public healthcare can create steps towards improving the overall health as well as PAP compliance in an underserved community.

\section{Competing interests}

The authors declare that they have no competing interests.

Authors' contributions

\begin{tabular}{|l|c|c|c|}
\hline Authors' contributions & TSB & MEW & JS \\
\hline Research concept and design & $\checkmark$ & -- & $\checkmark$ \\
\hline Collection and/or assembly of data & $\checkmark$ & -- & $\checkmark$ \\
\hline Data analysis and interpretation & $\checkmark$ & $\checkmark$ & -- \\
\hline Writing the article & $\checkmark$ & -- & -- \\
\hline Critical revision of the article & $\checkmark$ & $\checkmark$ & $\checkmark$ \\
\hline Final approval of article & $\checkmark$ & $\checkmark$ & $\checkmark$ \\
\hline Statistical analysis & $\checkmark$ & $\checkmark$ & -- \\
\hline
\end{tabular}

Publication history

Editors: Jennifer Quint, London School of Hygiene and Tropical Medicine, UK.

Basil O. Ibe, Harbor-UCLA Medical Center, USA.

EIC: Victor J. Thannickal, University of Alabama at Birmingham, USA. Received: 31-May-2014 Final Revised: 24-Aug-2014

Accepted: 26-Aug-2014 Published: 12-Sep-2014
2. Catcheside PG. Predictors of continuous positive airway pressure adherence. F1000 Med Rep. 2010; 2:70. | Article | PubMed Abstract | PubMed Full Text

3. Simon-Tuval T, Reuveni H, Greenberg-Dotan S, Oksenberg A, Tal A and Tarasiuk A. Low socioeconomic status is a risk factor for CPAP acceptance among adult OSAS patients requiring treatment. Sleep. 2009; 32:545-52. | PubMed Abstract | PubMed Full Text

4. Billings ME, Auckley D, Benca R, Foldvary-Schaefer N, Iber C, Redline S, Rosen CL, Zee P and Kapur VK. Race and residential socioeconomics as predictors of CPAP adherence. Sleep. 2011; 34:1653-8. | Article | PubMed Abstract I PubMed Full Text

5. Platt AB, Field SH, Asch DA, Chen Z, Patel NP, Gupta R, Roche DF, Gurubhagavatula I, Christie JD and Kuna ST. Neighborhood of residence is associated with daily adherence to CPAP therapy. Sleep. 2009; 32:799806. | PubMed Abstract | PubMed Full Text

6. Tzischinsky $O$, Shahrabani $S$ and Peled R. Factors affecting the decision to be treated with continuous positive airway pressure for obstructive sleep apnea syndrome. Isr Med Assoc J. 2011; 13:413-9. | Article | PubMed

7. Kim JH, Kwon MS, Song HM, Lee BJ, Jang YJ and Chung YS. Compliance with positive airway pressure treatment for obstructive sleep apnea. Clin Exp Otorhinolaryngol. 2009; 2:90-6. | Article | PubMed Abstract | PubMed Full Text

8. Joo MJ and Herdegen JJ. Sleep apnea in an urban public hospital: assessment of severity and treatment adherence. J Clin Sleep Med. 2007; 3:285-8. | PubMed Abstract | PubMed Full Text

9. Bakker JP, O'Keeffe KM, Neill AM and Campbell AJ. Ethnic disparities in CPAP adherence in New Zealand: effects of socioeconomic status, health literacy and self-efficacy. Sleep. 2011; 34:1595-603. | Article | PubMed Abstract | PubMed Full Text

\section{Citation:}

Burke TS, Wells ME and Singh J. Domiciliary continuous positive airway pressure therapy in an underserved population: compliance and influential factors. Pulmonol Respir Res. 2014; 2:1. http://dx.doi.org/10.7243/2053-6739-2-1

\section{References}

1. Kapur VK. Obstructive sleep apnea: diagnosis, epidemiology, and economics. Respir Care. 2010; 55:1155-67. | Article | PubMed 